\title{
Projected changes of temperature and precipitation in Texas from downscaled global climate models
}

\author{
Xiaoyan Jiang ${ }^{1,2}$, Zong-Liang Yang ${ }^{1, *}$ \\ ${ }^{1}$ Department of Geological Sciences, The John A. and Katherine G. Jackson School of Geosciences, \\ 1 University Station \#C1100, University of Texas, Austin, Texas 78712, USA \\ ${ }^{2}$ Present address: National Center for Atmospheric Research, 3450 Mitchell Lane, Boulder, Colorado 80301, USA
}

\begin{abstract}
Climate change projections, in particular precipitation and temperature under different IPCC future emissions scenarios in Texas, were based on statistically downscaled multi-model ensembles. A comparison of downscaled model results with observations and reanalysis data for the present-day climate shows that all models simulate monthly variations in surface air temperature well (correlation coefficient: 0.98 ), while precipitation correlation coefficients vary widely across different models (from 0.79 to 0.92 ). We performed a detailed analysis for the Texas region with an emphasis on 5 sub-regions. Our probability analysis shows an overall increase in surface air temperature towards the end of the 21 st century of $4.8,3.6$, and $2.2^{\circ} \mathrm{C}$ for $\mathrm{A} 2, \mathrm{~A} 1 \mathrm{~B}$, and $\mathrm{B} 1$ emission scenarios, respectively, relative to the mean of 1971-2000. Surface air temperatures in northwestern Texas increase more under various scenarios, while they are projected to increase steadily in southeastern Texas in response to the large thermal capacity of the Gulf of Mexico. The trends in precipitation are not as clear as those in temperature, suggesting more complicated mechanisms. Precipitation and surface air temperature changes are negatively correlated on an annual basis. This indicates that, as surface air temperature increases in Texas, most regions are projected to become drier. Precipitation changes correlate negatively with surface air temperature changes in summer, while no correlation appears between them for the winter season.
\end{abstract}

KEY WORDS: Downscaling $\cdot$ Emissions scenarios $\cdot$ Precipitation $\cdot$ Temperature $\cdot$ Future climate change

Resale or republication not permitted without written consent of the publisher

\section{INTRODUCTION}

Human-induced global and regional climate change has shown profound impacts on ecosystems, water resources, sea levels, extreme events, and human health (e.g. Walther et al. 2002, Kalnay \& Cai 2003, Karl \& Trenberth 2003, Patz et al. 2005) during the past $50 \mathrm{yr}$. These impacts may be further amplified as global temperatures continue to rise in response to increasing greenhouse gases. An annual to decadal assessment of future climate change on regional scales is crucial in understanding the public's vulnerability.

The Fourth Assessment Report (AR4) of the Intergovernmental Panel on Climate Change (IPCC 2007) showed a global warming of about $0.2^{\circ} \mathrm{C}$ decade $^{-1}$ for a range of emission scenarios outlined in the Special Report on Emissions Scenarios (SRES) over the next 2 decades. Even if the concentrations of greenhouse gases and aerosols were held constant at year 2000 levels, a $0.1^{\circ} \mathrm{C}$ decade ${ }^{-1}$ increase in global temperatures is projected (IPCC 2007). At local (e.g. county) to regional (e.g. state) scales, temperature changes are projected to be more variable. Utilizing output from global climate models, a number of studies have analyzed model projections of future climate change for different regions under different emissions scenarios (e.g. Boer et al. 2000, Johns et al. 2003, Seager et al. 2007, Cayan et al. 2008). With regard to precipitation changes, climate models project more precipitation in some regions as a result of an increase in 
the total amount of water in the atmosphere under a warming climate (Wentz et al. 2007), while mid-latitude regions, are projected to have less precipitation (IPCC 2007).

The present analysis focuses on Texas, which is home to 4 of the top 10 fastest growing cities in the USA, and also a very productive agricultural state. Increases in climate variability could make adaptation by farmers more difficult. A warmer climate and increased evaporation may increase the need for irrigation. As the state population is projected to double by 2060, demand for water is projected to increase by $27 \%$ (www.twdb.state.tx.us/wrpi/data/proj/ 2012popproj.asp).

Projected impacts of climate change in Texas have previously been assessed based on global climate model simulations and downscaled regional climate information. By use of a scaling method on global climate model simulations, Loaiciga et al. (2000) demonstrated the vulnerability of the Edwards aquifer, an important water resource for Texas, to climate change. Using geographic information systems, vegetation models, and general circulation models, Cameron \& Scheel (2001) revealed that climate change could have a large impact on regional distributions of vegetation and rodents. Based on simulations of several global climate models, Seager et al. (2007) showed that southwestern North America, which encompasses part of Texas, is projected to become drier in the 21st century, and that the transition to a more arid climate should already be underway. Jiang et al. (2008) investigated the impacts of climate change on Texas air quality using a regional climate model and future climate scenario, suggesting that climate change could have a large effect on ozone formation and high ozone episodes. The present study analyzes climate change in Texas on the basis of 16 downscaled global climate models under various emissions scenarios.

International climate modeling groups have produced hundreds of simulations at a coarse resolution, representing past and future climates for the IPCC AR4 (Meehl et al. 2007). The regional climate information projected by these global climate models is not adequate for impact assessments (e.g. risk of droughts or floods) that require climate information at finer resolutions. For example, hydrological and crop models often require climate information at a very fine spatial resolution (e.g. Mearns et al. 1997, Wood et al. 2002). Methods to downscale coarseresolution climate information to regional scales have been developed (e.g. Kidson \& Thompson 1998, Mearns et al. 1999, Murphy 1999, Liang et al. 2006,
Fowler et al. 2007, Schmidli et al. 2007, Lo et al. 2008). Dynamic downscaling and statistical downscaling are the 2 primary methods employed (e.g. Wilby \& Wigley 1997, IPCC 2001). Dynamic downscaling, which involves the use of regional climate models, has the advantage of taking into account regional features such as land use and terrain in simulations, but is more computationally expensive (e.g. Liang et al. 2006, Lo et al. 2008). Statistical downscaling, based on the development of relationships linking the local variables to atmospheric-predictor variables (Wilby \& Wigley 1997), is more affordable. Wood et al. (2004) found that a bias correction-based statistical downscaling method outperforms others including the dynamic downscaling method, whereas Schmidli et al. (2007) compared 6 statistical downscaling models and 3 regional climate models and found that statistical downscaling models underestimated the magnitude of year-to-year variations in simulated precipitation compared to dynamic downscaling models.

The US Department of Interior's Bureau of Reclamation (Research \& Development Office) and the Lawrence Livermore National Laboratory (LLNL), teamed with other research institutes, have developed statistically downscaled climate projections (monthly temperature and precipitation) on the basis of the World Climate Research Programme (WCRP) Coupled Model Intercomparison Project phase 3 (CMIP3) multi-model data set. They used a method originally developed by Wood et al. (2004) to downscale the global climate model data sets to region scale over the USA. This method is computationally efficient enough to be applied to many projections (e.g. Maurer 2007).

In the present study, the statistically downscaled WCRP CMIP3 Climate Projections are used to detect signals of future climate change for Texas with a focus on precipitation and temperature changes under 3 different future emissions scenarios. The model performance is evaluated using available observations and reanalysis data. Part of the effort at evaluation is focused on analyzing general trends of climate change in terms of trend analysis and interannual variability. Seasonal changes in precipitation and temperature are presented. The large size of Texas and its unique location at the intersection of different climate zones - humid subtropical, temperate semiarid, and subtropical steppe-make it necessary to study changes for different regions. We define 5 subregions in Texas (Fig. 1), based on the fact that these regions historically have experienced different climates varying widely from arid in the west to wet in 


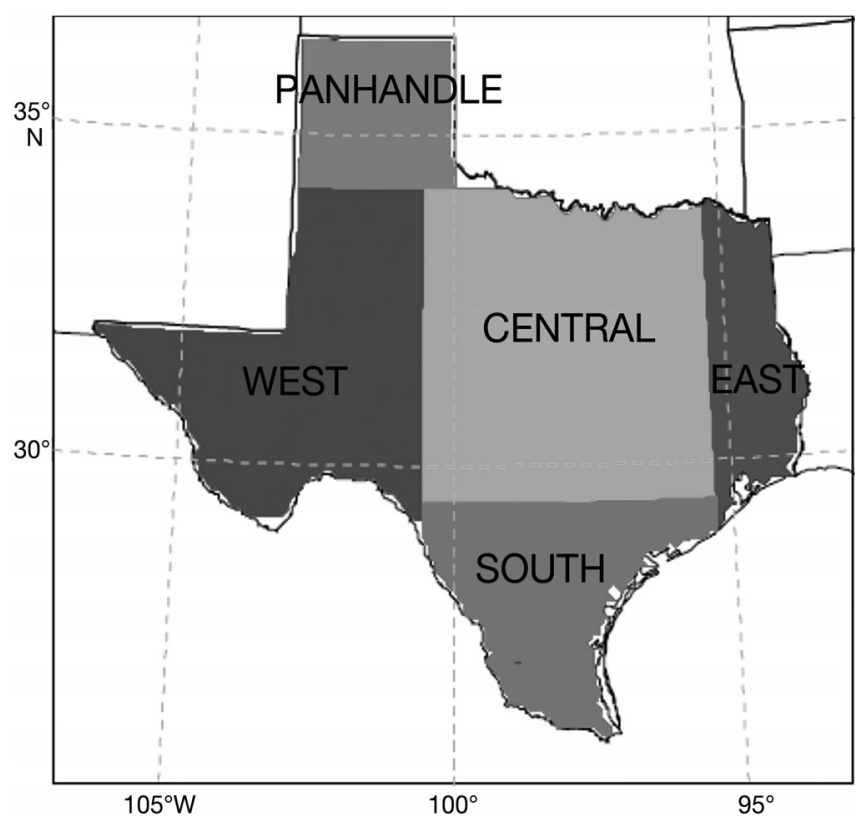

Fig. 1. Five sub-regions of Texas

Table 1. Global climate models used in World Climate Research Programme (WCRP) Coupled Model Intercomparison Project phase 3 (CMIP3) data

\begin{tabular}{|c|c|}
\hline Model & Modeling group \\
\hline BCCR-BCM2.0 & Bjerknes Centre for Climate Research, Norway \\
\hline CGCM3.1 (T47) & $\begin{array}{l}\text { Canadian Centre for Climate Modeling \& Analysis, } \\
\text { Canada }\end{array}$ \\
\hline CNRM-CM3 & $\begin{array}{l}\text { Météo-France/Centre National de Recherches } \\
\text { Météorologiques, France }\end{array}$ \\
\hline CSIRO-Mk3.0 & CSIRO Atmospheric Research, Australia \\
\hline GFDL-CM2.0 & US Dept. of Commerce/NOAA/Geophysical Fluid \\
\hline GFDL-CM2.1 & Dynamics Laboratory, USA \\
\hline GISS-ER & NASA/Goddard Institute for Space Studies, USA \\
\hline INM-CM3.0 & Institute for Numerical Mathematics, Russia \\
\hline IPSL-CM4 & Institut Pierre Simon Laplace, France \\
\hline MIROC3.2 (medres) & $\begin{array}{l}\text { Center for Climate System Research (University of } \\
\text { Tokyo), National Institute for Environmental } \\
\text { Studies, and Frontier Research Center for Global } \\
\text { Change (JAMSTEC), Japan }\end{array}$ \\
\hline ECHO-G & $\begin{array}{l}\text { Meteorological Institute of the University of Bonn, } \\
\text { Meteorological Research Institute of KMA, } \\
\text { Germany }\end{array}$ \\
\hline ECHAM5/MPI-OM & Max Planck Institute for Meteorology, Germany \\
\hline MRI-CGCM2.3.2 & Meteorological Research Institute, Japan \\
\hline CCSM3 & National Center for Atmospheric Research, USA \\
\hline PCM & National Center for Atmospheric Research, USA \\
\hline UKMO-HadCM3 & $\begin{array}{l}\text { Hadley Centre for Climate Prediction and } \\
\text { Research/Met Office, UK }\end{array}$ \\
\hline
\end{tabular}

the east. Finally, the relationships between precipitation and surface air temperature changes over Texas are examined. The methodologies described in this study are applicable to other regions under different climate scenarios.

\section{DATA AND METHODS}

The present study uses the downscaled WCRP CMIP3 multi-model data set for 3 IPCC SRES emissions scenarios: A2, A1B, and B1 (Nakicenovic et al. 2000).

The WCRP CMIP3 data set (www-pcmdi.llnl.gov/ ipcc/diagnostic_subprojects.php) consists of 39, 36, and 37 simulations provided by 16 climate models for the A1B, A2, and B1 scenarios, respectively (Table 1), with some models generating more than one simulation for one scenario. Therefore, this data set includes a total of 112 transient simulations for the 20th century and 21st century under the 3 scenarios. A statistical downscaling approach-basically a bias correction technique, first introduced by Wood et al. (2004) — was employed to generate downscaled highspatial-resolution products (http://gdodcp.ucllnl.org/downscaled_cmip3_ projections). For bias removal, a quantile-based mapping was constructed from the global climate model climatology to the observed monthly climatology for each variable (temperature and precipitation). The success of the method depends on the stability of the probability distributions used to correct climate model bias. Details were reported in Wood et al. (2004) and Maurer (2007). In their technique, they assumed that the processes controlling the climate at the fine grid scale during the period of 1950-1999 would continue to govern local climate features in the future. Although this is a limit of their approach, Wood et al. (2004) showed that this bias correction method outperformed others, including dynamic downscaling approaches. Thus, in the present study, we only briefly evaluate the statistically downscaled climate model results against observations. Multi-model ensemble results of precipitation and surface air temperature are also used to assess 
potential future climate change in Texas under different emission scenarios, with an emphasis on the A1B scenario. The spatial resolution of this data set is $1 / 8^{\circ}$ $(\sim 12 \mathrm{~km})$ for the contiguous USA.

\section{PRESENT-DAY CLIMATE EVALUATION}

One observation data set used for evaluation was from the USA National Climatic Data Center (NCDC). The data were adjusted to account for effects of factors such as instrument changes, station relocations, observer practice changes, and urbanization (www. ncdc.noaa.gov/oa/ncdc.html). The National Centers for Environmental Prediction (NCEP) North American Regional Reanalysis (NARR) data set (Mesinger et al. 2006) was also used for model evaluation. The NARR data were generated at a $3 \mathrm{~h}$ interval with the use of the NCEP Eta model, its data assimilation system, and a recent version of the Noah land surface model at a spatial resolution of $32 \mathrm{~km}$. The system used to generate the NARR data also includes hourly assimilation of observed precipitation. We compare the 1980-2000 means of monthly average NCDC and
NARR surface air temperature and precipitation with the downscaled WCRP CMIP3 data. The reason for selecting the period of $1980-2000$ is that the NARR data are only available since 1979.

Overall, the downscaled surface air temperature and precipitation agree well with the NARR data over the entire domain (Fig. 2). Downscaled model results reproduce well the main features of monthly variations in surface air temperature (Fig. 3a). If we consider the NCDC data as true observations, there is a warm bias in the NARR data as a result of unsuccessful assimilation of land surface temperature observations (Mesinger et al. 2006) in the data assimilation scheme (3DVAR). Because of the large diurnal variation of temperature over land that exists at any time of year, residuals between observations and background required by the 3DVAR scheme of the NARR system are regularly quite large. The balance relationship in the 3DVAR erroneously connects these large surface residuals to the wind field, which has a relatively large vertical correlation length (around 250-300 mb). As a result, the large surface residuals have an undesirable impact on lowertropospheric temperatures and lower- to mid-
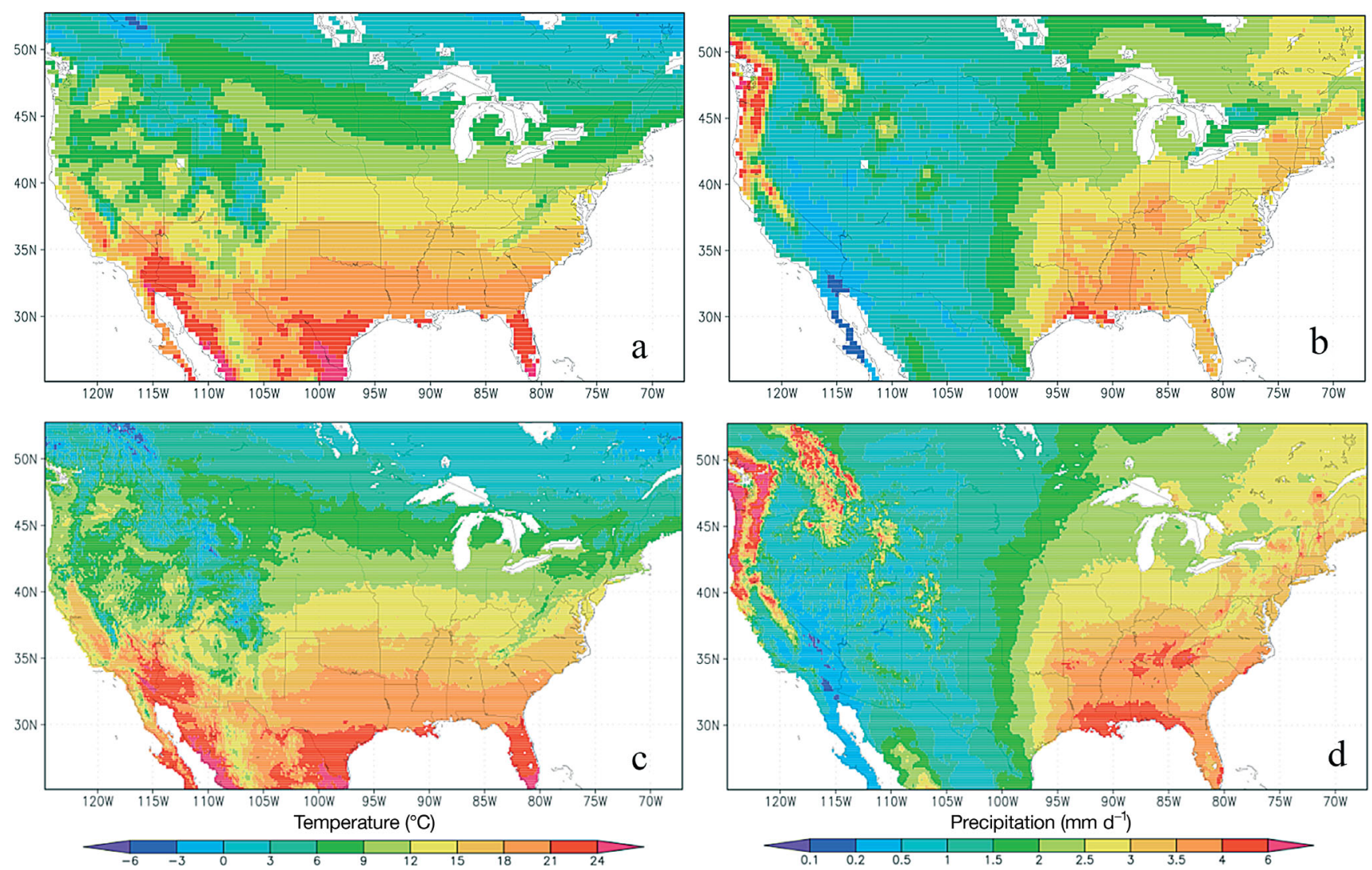

Fig. 2. Comparison of $(\mathrm{a}, \mathrm{b})$ North American Regional Reanalysis (NARR) and $(\mathrm{c}, \mathrm{d})$ downscaled annual mean $(\mathrm{a}, \mathrm{c})$ surface air temperature $\left({ }^{\circ} \mathrm{C}\right)$ and $(\mathrm{b}, \mathrm{d})$ precipitation $\left(\mathrm{mm} \mathrm{d}^{-1}\right)$ over the period $2000-2007$ 

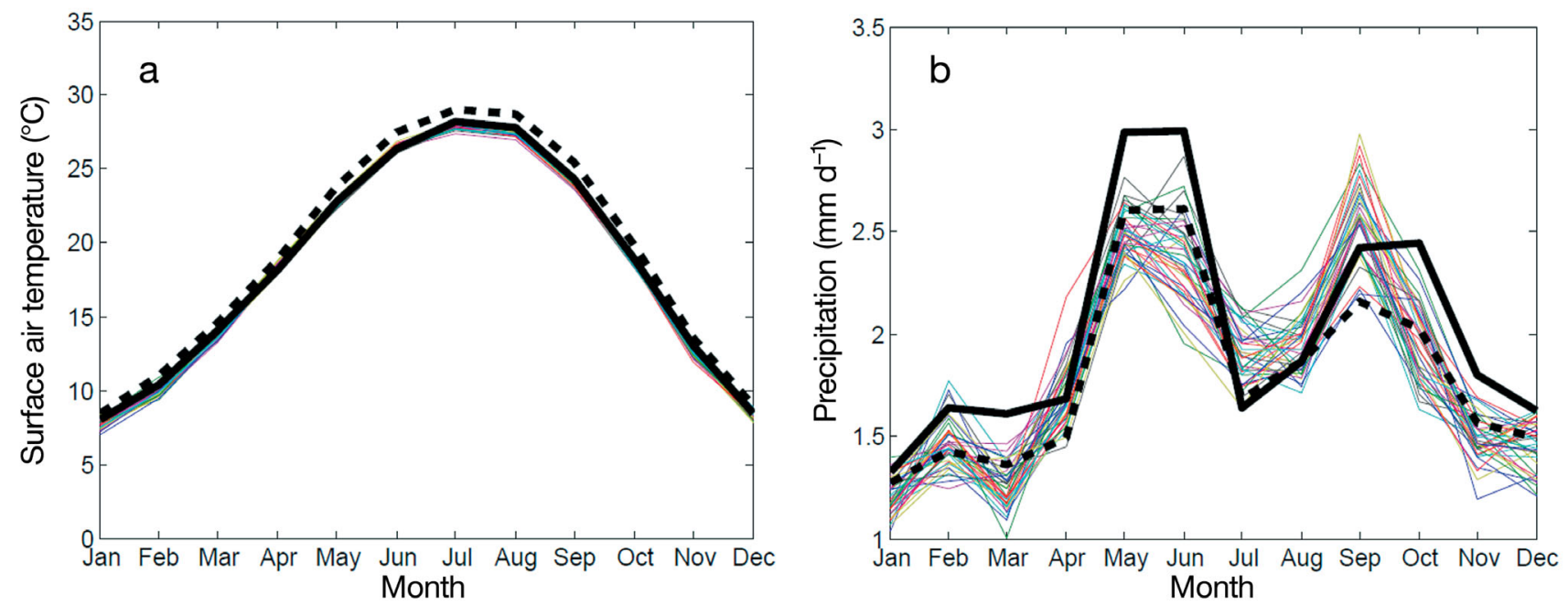

Fig. 3. National Climatic Data Center (NCDC) observations (thick solid line), North American Regional Reanalysis (NARR) data (thick dashed line), and downscaled model results (colored lines) over all of Texas for (a) monthly mean surface air temperature and (b) monthly mean precipitation over the period 1980-2000

tropospheric winds, instead of being limited to the boundary layer. Therefore, surface air temperature in the NARR data is simulated using the Noah land surface model, which suffers from several biases in near-surface fields due to errors in the partitioning of boundary layer fluxes. The warm bias is mainly owing to an overestimate of sensible heat flux at the cost of latent heat flux. Hence, we attribute the warm bias in the NARR data to the lack of assimilation of ground-based surface temperature measurements in the NARR system.

Model performance in simulating precipitation varies (Fig. 3b). Overall, downscaled model results match well with the NARR precipitation data. The high quality of the NARR precipitation data is attributed to the assimilation of several sources of precipitation data sets including the Climate Prediction Center (CPC) precipitation and Higgins data over the USA continental area, and CMAP and CMORPH over southern portions of the oceans in the NARR system. The quality control performed on the CPC data (e.g. duplicate station check, standard deviation check) and radar and satellite data greatly improves the quality of precipitation data used in the NARR system (Higgins et al. 2000). No quality control was made of the NCDC precipitation data using radar or satellite data. The downscaled precipitation is overestimated in September compared to the NARR precipitation data, and the spread among climate models is larger than that in surface air temperature.

Correlation coefficients for surface air temperature between the NCDC observations and the downscaled model results (data not shown) are around 0.98 over the whole of Texas. The correlation coefficients for precipitation vary across models (Fig. 4). GFDLCM2.1 and IPSL-CM4 have the highest correlation coefficients (>0.9), while CNRM-CM3 has the lowest correlation coefficient $(\sim 0.79)$. To further assess the downscaled results, we calculated model biases (Fig. 5a,b) and normalized root mean square errors (RMSEs) for temperature and precipitation (Fig. 5c,d). Normalized RMSE values can be used to judge the extent to which the simulations differ from the observations. Models have smaller biases for winter precipitation and summer surface air temperature than for summer precipitation and winter surface air temperature. Models that perform best in simulating temperatures do not necessarily simulate precipitation

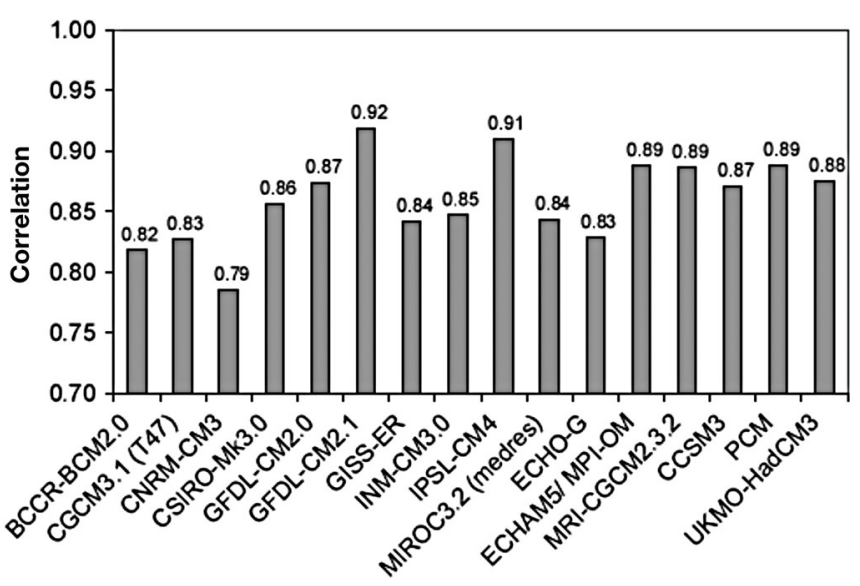

Fig. 4. Correlation coefficients of monthly precipitation between downscaled results (16 models) and National Climatic Data Center (NCDC) observations over entire Texas. See Table 1 for abbreviations 

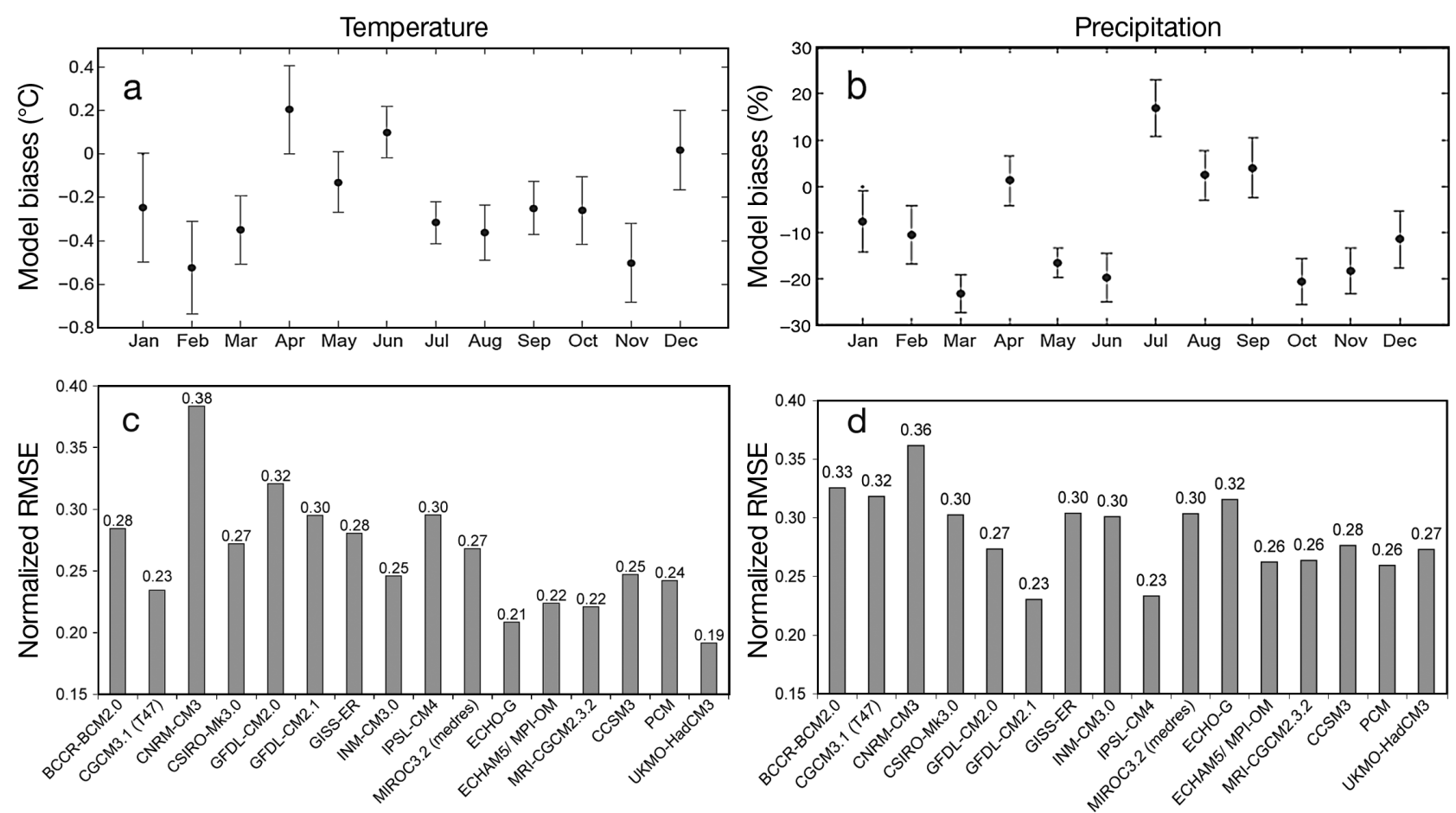

Fig. 5. Model biases for monthly mean (a) surface air temperature $\left({ }^{\circ} \mathrm{C}\right)$ and (b) precipitation $(\%)$ between downscaled results and National Climatic Data Center (NCDC) observations; normalized root mean square error (RMSE) of (c) surface air temperature and (d) precipitation for each model over Texas. See Table 1 for abbreviations

well. CNRM-CM3 has the largest normalized RMSE for surface air temperature and precipitation, suggesting it is not good for climate assessment studies over Texas. ECHO-G and UKMO-HadCM3 are the best among all of the downscaled climate models for surface air temperature simulations. Again, GFDLCM2.1 and IPSL-CM4 are good at simulating precipitation over Texas, as shown by smaller normalized RMSE values. Although there are biases in different climate models, we assume that biases in simulating the present-day climate are systematically propagated into the projected future climate (Liang et al. 2008). This could give rise to some uncertainty in future climate projections for Texas.

\section{PROJECTED TEMPERATURE AND PRECIPITATION CHANGES}

\subsection{Temperature}

IPCC climate models projected an overall warming trend towards the end of the 21st century all over the world (IPCC 2007). As shown in Fig. 6a, temperatures over Texas are projected to increase under the 3 different emissions scenarios, with the highest increase associated with the A2 scenario. The warming during
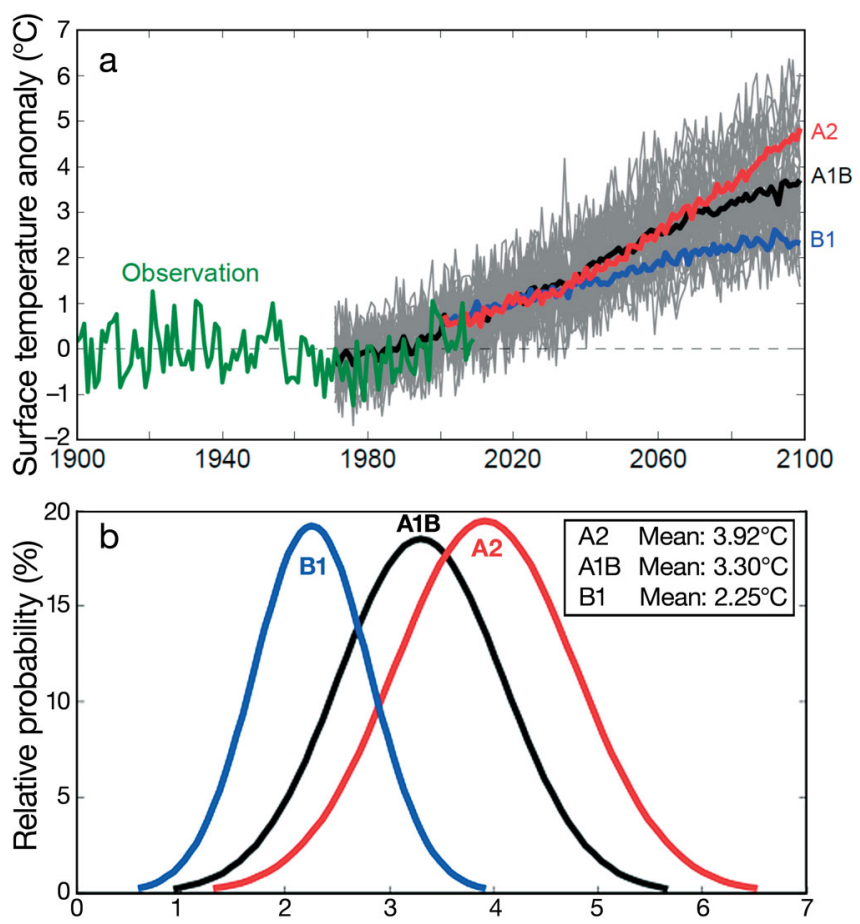

Fig. 6. (a) Projected surface air temperature anomalies for the period 2001-2099 over Texas relative to 1971-2000 means. All model results for the A1B scenario (gray line); ensemble means for the A1B (black line), A2 (red line), and B1 (blue line) scenarios; and observations (green line) are shown. (b) Projected probability distributions of surface air temperature changes for the period 2070-2099 relative to 1971-2000 
the 21 st century is approximately linear with time under each scenario, although there are year-to-year variations. NCDC observations show strong year-toyear variation, while the ensemble means do not. This can be explained thus: when we averaged all model results, we removed high-frequency information. This type of feature is also observed in the IPCC AR4 report for global temperature projections (IPCC 2007). The ensemble means of model-simulated surface air temperature for the present day are in the range of observed variations. The temperature increase is somewhat modest from 2000 to 2040, but becomes more marked afterwards. It is projected that a relatively small increase in temperatures is likely to occur under the B1 scenario. Projected temperature increases over Texas will reach $4.8,3.6$, and $2.2^{\circ} \mathrm{C}$ by the end of 2100 under the $\mathrm{A} 2, \mathrm{~A} 1 \mathrm{~B}$, and $\mathrm{B} 1$ scenarios, respectively. We only plotted all model results, as indicated by the gray color in Fig. 6a, for the A1B scenario. It shows that there is a large spread among models due to differences in model parameterizations, sensitivities, and responses to greenhouse gases and other forcings.

The probability plot of projected surface air temperature changes (Fig. 6b) shows a range of positive anomalies over the period of 2070-2099 from +0.6 to $+6.5^{\circ} \mathrm{C}$. Table 2 shows that, under the A2 scenario, about $10 \%$ of the models project an increase of $5.2^{\circ} \mathrm{C}$ in surface air temperature. Half of the models project a $4.1^{\circ} \mathrm{C}$ increase. Most $(\sim 90 \%)$ of them project that there will be at least a $3.0^{\circ} \mathrm{C}$ increase in surface air temperature. Increases under the B1 scenario are the smallest, and the A2 scenario yields the highest temperature increase.

Temperatures in northwestern Texas increase more, with trends ranging from approximately $2.4^{\circ} \mathrm{C}$ under the B1 scenario to $4.2^{\circ} \mathrm{C}$ under the A2 scenario (Fig. 7). Projected temperature changes occur rather steadily in southeastern Texas, with annual temperature increases ranging from 2 to $3.2^{\circ} \mathrm{C}$ under the $\mathrm{B} 1$ and A2 scenarios. This could be attributed to the large thermal capacity of the Gulf of Mexico. The temperature gradient becomes stronger as emissions forcing increases.

Table 2. Temperature increase $\left({ }^{\circ} \mathrm{C}\right)$ from the $1971-2000$ period to the $2070-2099$ period predicted by $10 \%, 50 \%$, and $90 \%$ of all models

\begin{tabular}{|lccc|}
\hline No. of models (\%) & A2 & A1B & B1 \\
\hline 10 & 5.2 & 4.5 & 3.2 \\
50 & 4.1 & 3.0 & 2.3 \\
90 & 3.0 & 2.5 & 1.8 \\
\hline
\end{tabular}
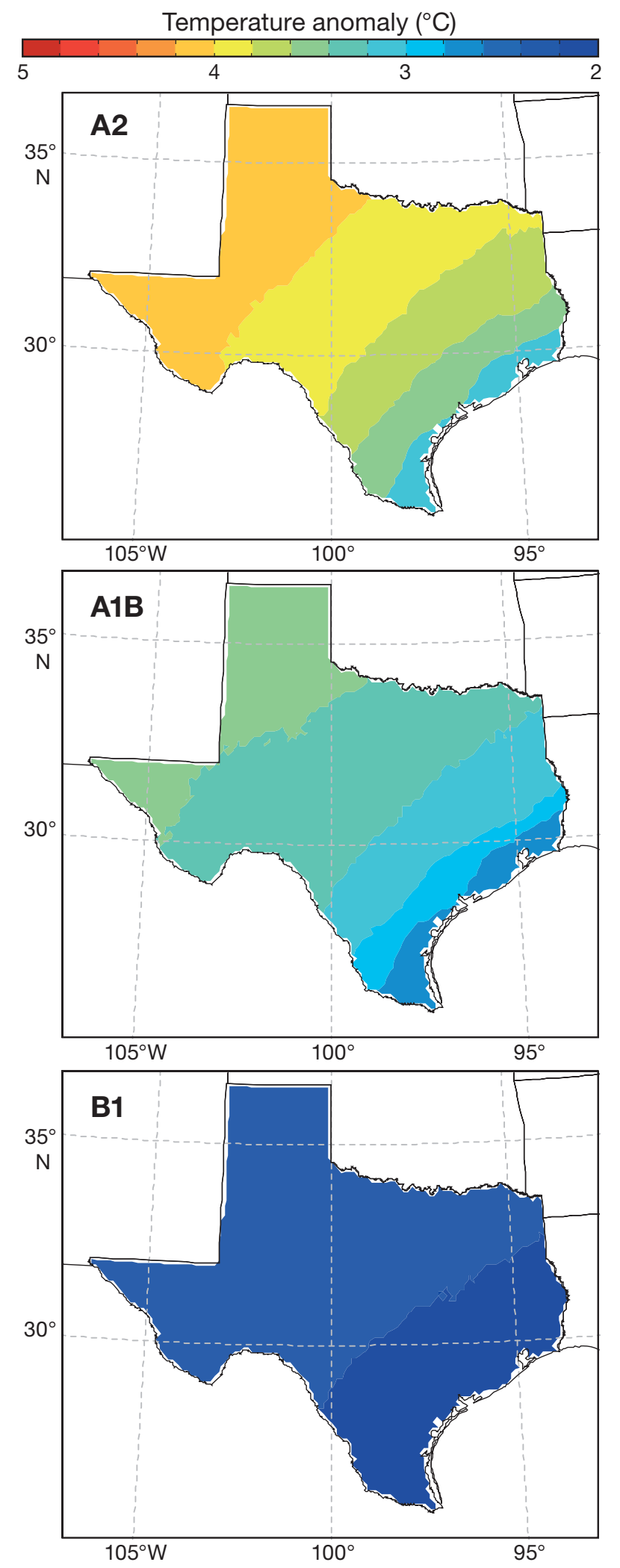

Fig. 7. Projected annual surface air temperature anomalies $\left({ }^{\circ} \mathrm{C}\right)$ for the period $2070-2099$ relative to $1971-2000$ means over Texas under different emissions scenarios 


\subsection{Precipitation}

An increase in the average global temperatures will likely to lead to changes in precipitation and atmospheric moisture because of changes in atmospheric circulation and increases in evaporation and water vapor. Model projections of future climate in southwestern North America show a transition to a more arid climate that began in the late 20th and early 21st centuries (Seager et al. 2007). While it is not easy to detect the projected trends in precipitation changes in Texas (data not shown), owing to large year-to-year variability of precipitation, careful examination reveals a slightly decreasing trend under the A1B scenario and a slightly increasing trend under the B1 scenario. The decreasing trend under the A2 scenario is relatively more conspicuous. A more sophisticated analysis is needed to discern the future changes in precipitation. For this purpose, in Section 5, a wavelet analysis tool is applied to precipitation data over 5 sub-regions in Texas. We will discuss this in more detail in Section 5.

The means of precipitation change under the 3 emissions scenarios are quite close, whereas a wetting trend is observed under the B1 scenario and a drying trend is present under the A2 scenario (Fig. 8a). The largest standard deviations are seen under the A2 scenario, while the smallest ones are observed under the B1 scenario. This suggests that more extremes of precipitation are projected to occur under the A2 scenario, which is not unexpected as the A2 scenario is the high-emissions scenario. As a result of projected increases in future temperature, precipitation extremes are projected to increase (Fig. 8b). A high risk of extreme precipitation events is likely to occur over the period 2070-2099; however, it should be noted that the averaged anomalies are around zero, indicating no big changes found in the annual-averaged precipitation over the entire state. Different climates in different regions over Texas might offset each other. Different seasonal changes in precipitation could reduce the annual changes as well (see Section 5).

\subsection{Changes in seasonal patterns of temperature and precipitation}

Simulations under the 3 scenarios all show more warming in summer than in winter (Fig. 9). As pointed out in Section 4.1, a much higher temperature increase is projected under the A2 scenario. Surface air temperatures are projected to increase by
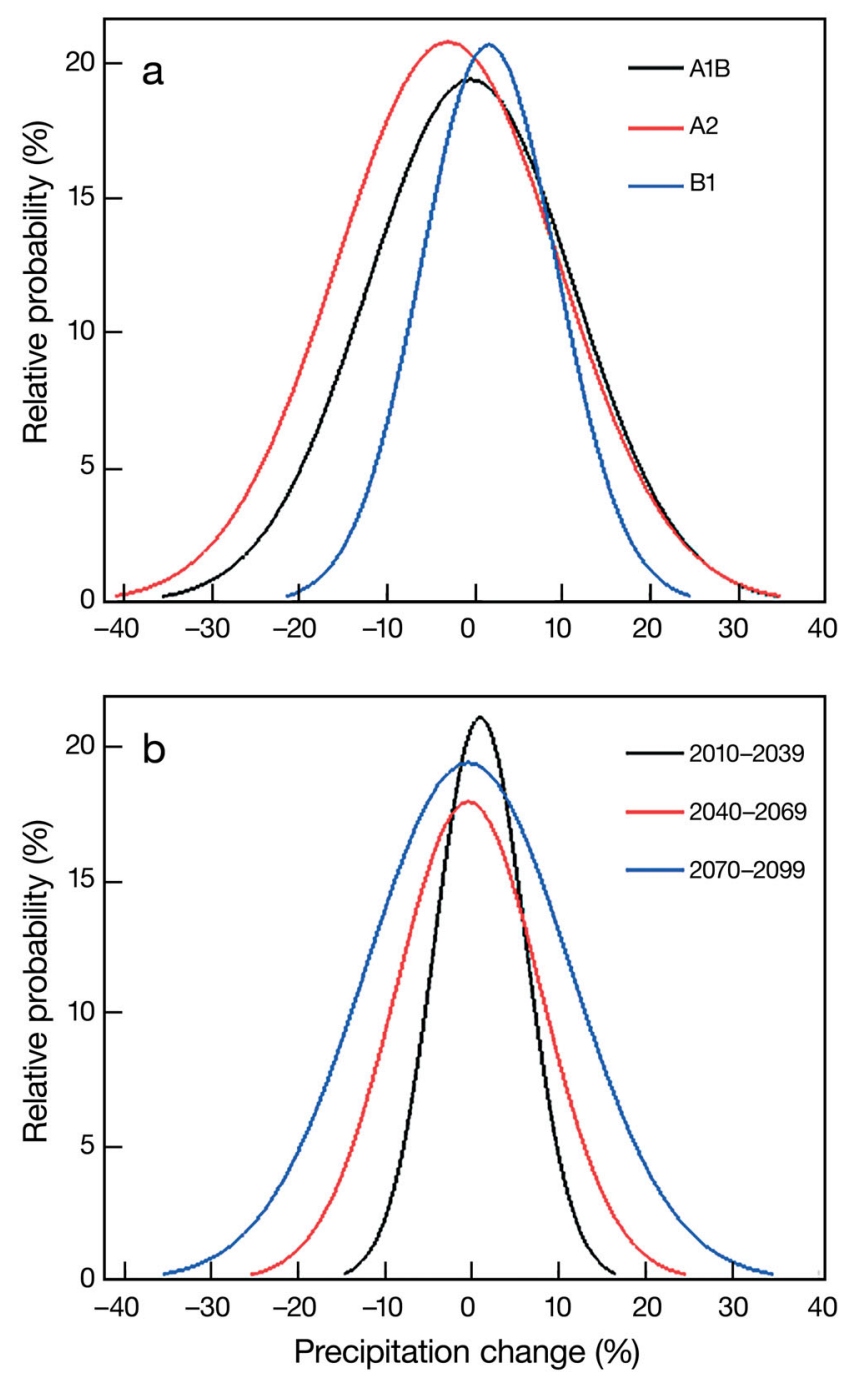

Fig. 8. (a) Projected probability distributions of precipitation changes under the 3 emissions scenarios for the period 2070-2099 relative to 1971-2000 means over Texas, based on a histogram plot of the precipitation changes with a fitted normal distribution. (b) Projected probability distributions of annual precipitation changes under the A1B scenario

$2.30^{\circ} \mathrm{C}$ on an annual basis, and $2.49^{\circ} \mathrm{C}$ and $1.92^{\circ} \mathrm{C}$ for summers and winters during the period 2040-2069 (Table 3). By the end of the 21st century, the increases in annual, summer, and winter temperatures are projected to reach $3.92,4.17$, and $3.29^{\circ} \mathrm{C}$, respectively (Table 3 ). The projected difference in temperature increases between the A2 and A1B scenarios is larger during the period 2070-2099, indicating more warming is likely to occur at the end of the 21 st century. The B1 scenario leads to a projected $2^{\circ} \mathrm{C}$ increase in annual temperature and smaller seasonal variations. Note that the spatial patterns of projected temperature changes for the 3 scenarios are 


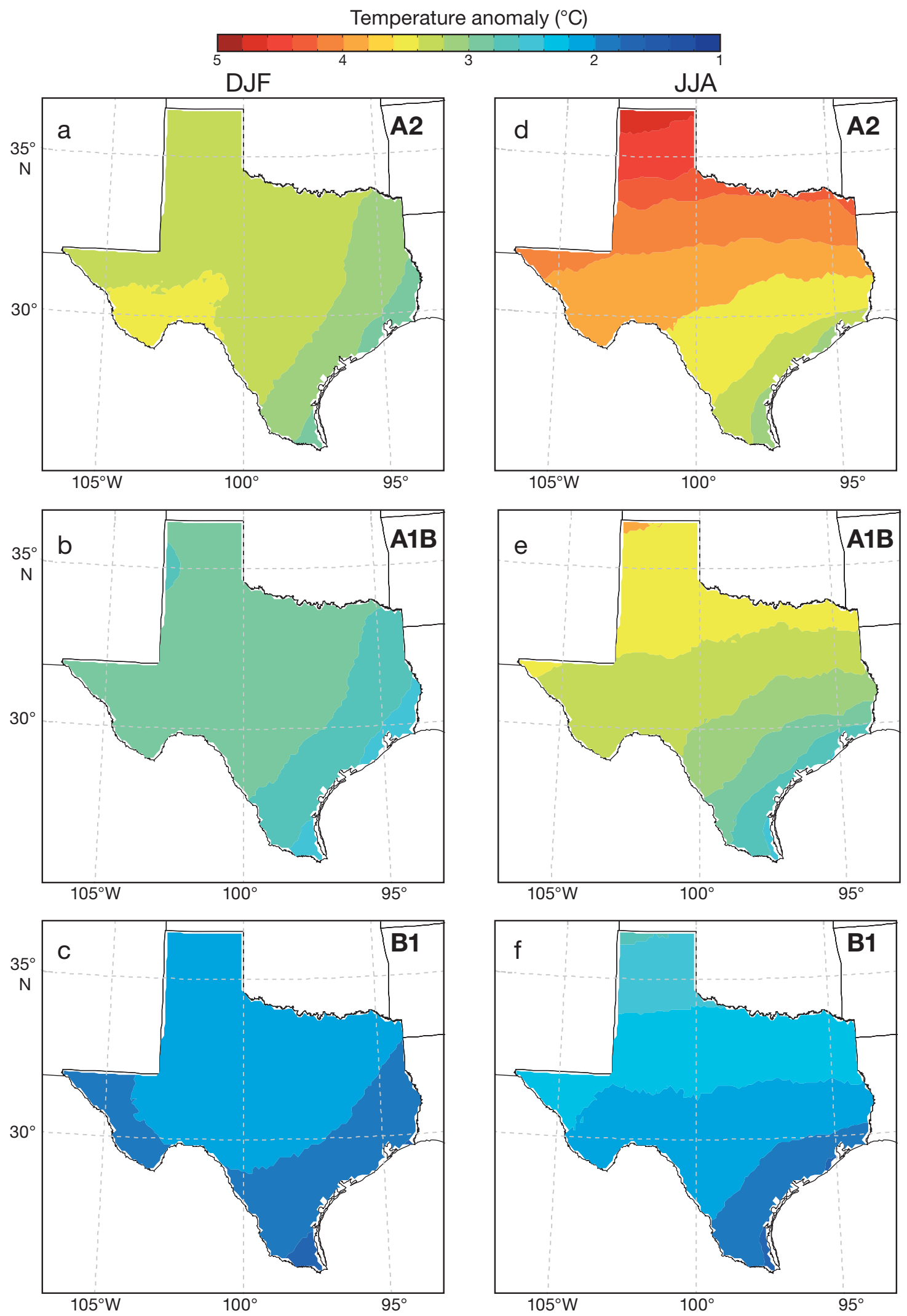

Fig. 9. Projected $(\mathrm{a}-\mathrm{C})$ winter (DJF: Dec-Jan-Feb) and (d-f) summer (JJA: Jun-Jul-Aug) surface air temperature changes $\left({ }^{\circ} \mathrm{C}\right)$ between 2070-2099 and 1971-2000 under the 3 emissions scenarios over Texas 
Table 3. Changes in temperature and precipitation over different periods relative to the baseline period 1971-2000. The unit for precipitation for the baseline period is $\mathrm{mm} \mathrm{d}^{-1}$

\begin{tabular}{|lcccrrrr|}
\hline \multicolumn{5}{|c}{ Temperature $\left({ }^{\circ} \mathrm{C}\right)$} & \multicolumn{2}{c|}{ Precipitation (\%) } \\
Annual Summer Winter & Annual Summer Winter \\
\hline $\begin{array}{r}1971-2000 \\
17.15\end{array}$ & 26.18 & 7.72 & 1.86 & 2.26 & 1.28 \\
$2040-2069$ & & & & & \\
A2 & 2.30 & 2.49 & 1.92 & -1.36 & -0.49 & -2.27 \\
A1B & 2.34 & 2.50 & 1.97 & -0.41 & 1.04 & -2.06 \\
B1 & 1.74 & 1.86 & 1.44 & 0.23 & 1.59 & -0.97 \\
$2070-2099$ & & & & & \\
A2 & 3.92 & 4.17 & 3.29 & -3.02 & -1.08 & -6.19 \\
A1B & 3.30 & 3.44 & 2.85 & -0.41 & 3.05 & -3.42 \\
B1 & 2.25 & 2.33 & 2.02 & 1.53 & 4.91 & -2.67 \\
\hline
\end{tabular}

very similar, with larger increases seen in northwestern Texas and smaller increases seen in southeastern Texas, but they differ in their magnitudes.

Changes in precipitation in different seasons are projected to trend southwest-northeast, with relatively larger changes in the southwest (Fig. 10). The observed precipitation gradients in Texas are in a west-east direction. So the changes in future precipitation do not exactly match the observed precipitation gradients. Most regions are projected to experience reduced precipitation in winters under global warming, except for the Panhandle region. The decrease in winter precipitation can be as large as $20 \%$. The degree of future drying trend is most obvious under the A2 scenario. The B1 scenario produces modest drying climates in winters. In contrast, summers are likely to become wetter over southwestern Texas under all scenarios. Nearly half of the area is projected to be wetter in summer under the A2 scenario, and threequarters of the area is projected to have more precipitation under the A1B scenario, with the largest increase reaching $>10 \%$. If the scenario is $\mathrm{B} 1$, the wetting trend expands all over Texas. If we average precipitation changes over the entire state, the wet summers and dry winters will offset each other. The summary of precipitation changes over Texas is listed in Table 3. The results for precipitation changes suggest that the southwest region of Texas is more vulnerable to future climate change.

\section{SUBREGIONAL CLIMATE CHANGE UNDER A1B SCENARIO}

For the sake of simplicity, we only examine future climate change for the 5 sub-regions in Texas under the mid-level A1B scenario. We calculated $95 \%$ confidence intervals for temperature and precipitation changes using ANOVA (Dean \& Voss 1999). The Panhandle region is projected to have larger increases in surface air temperature, whereas South Texas is projected to experience smaller increases (Fig. 11a). The difference in temperatures between the 2 regions is around $0.5^{\circ} \mathrm{C}$. Temperatures in other regions are projected to increase by about $3.0^{\circ} \mathrm{C}$. The confidence interval plot for precipitation (Fig. 11b) suggests big uncertainties in future precipitation projections, as indicated by the large intervals over different sub-regions. The climate models project a drier climate towards the end of the 21st century over much of the Texas region except for East Texas, which is more influenced by the Gulf of Mexico.

To assess the long-term trend in precipitation changes, a detrending method is needed because precipitation often contains multiple signals and has segments of increasing and decreasing trends. Among a variety of techniques available for analyzing variability, wavelet analysis has emerged in the last decade as a useful statistical tool for this purpose (e.g. Almasri et al. 2008). The wavelet method can detrend time series according to time and scale simultaneously. It can perform a local analysis, revealing aspects of data that other signal analysis techniques miss, such as trends, abrupt changes, breakdown points, and discontinuities. The discrete wavelet analysis (DWT) using the Wavelet Toolbox for Matlab was applied; precipitation time series decomposition was performed 2 times (level 2) using Daubechies family (db) at order 4. Fig. 12 exhibits the trends of annual precipitation changes $\left(\mathrm{mm} \mathrm{d}^{-1}\right)$ for the 5 sub-regions. The results show drying trends for 4 of the 5 sub-regions: South Texas, Central Texas, East Texas, and the Panhandle region. In West Texas, the trend is not discernible. Nevertheless, there are some periods with precipitation increases.

South Texas and West Texas have similar patterns in precipitation changes on a monthly basis (Fig. 13). Starting from November to April, the 2 regions tend to become much drier, and the precipitation changes during the period 2070-2099 relative to the period 1971-2000 can be as much as $-15 \%$. From June to September, there is a $5 \%$ increase in precipitation over the 2 regions. East and Central Texas are projected to become drier in winter and wetter in summer in the future, but the changes in precipitation are not as notable as those seen in South and West Texas. In the Panhandle region, winter is projected to have more rainfall, while spring and fall are projected to have less rainfall. There is no big change in summer 


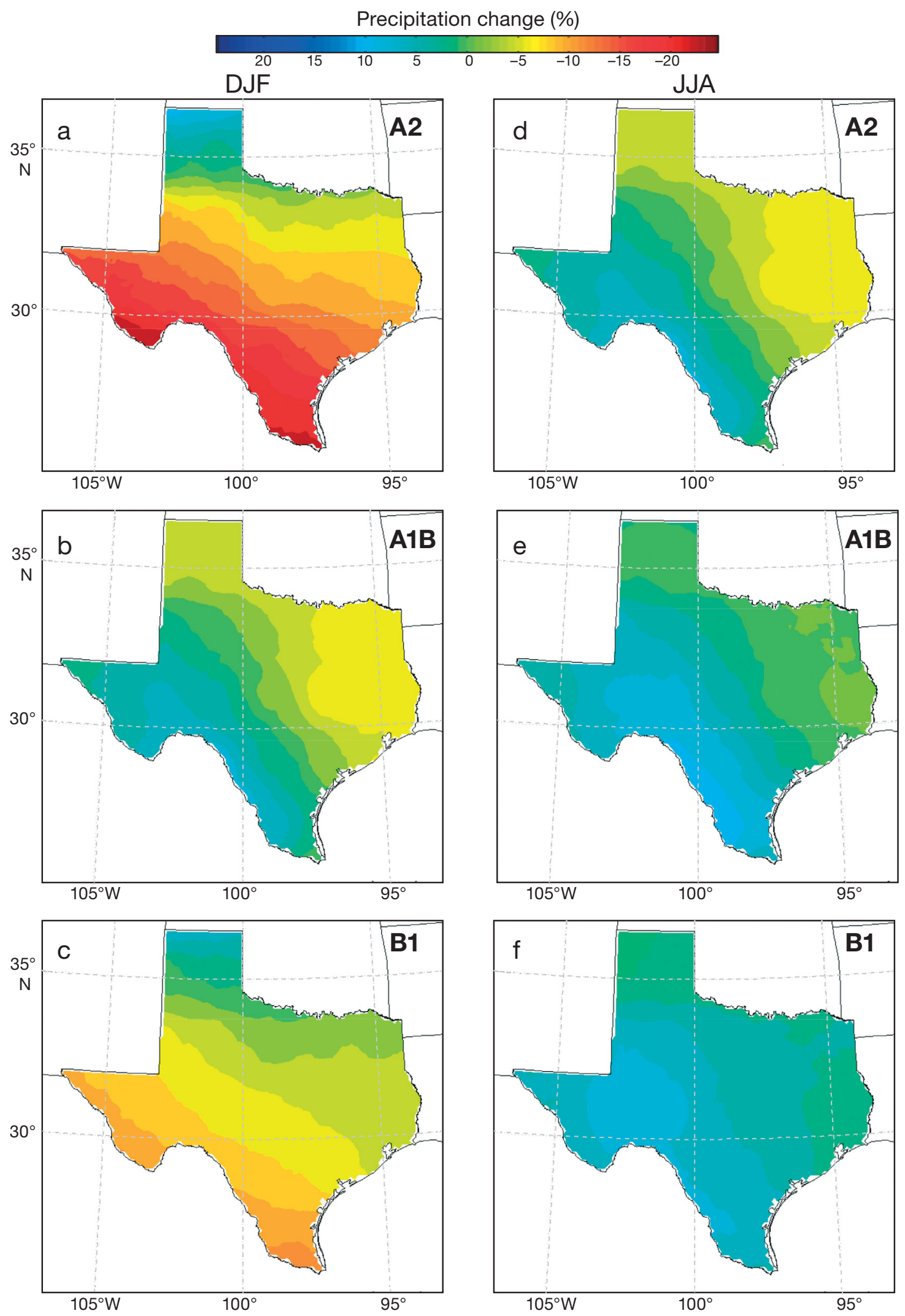

Fig. 10. As in Fig. 9, but for projected precipitation changes (\%) 

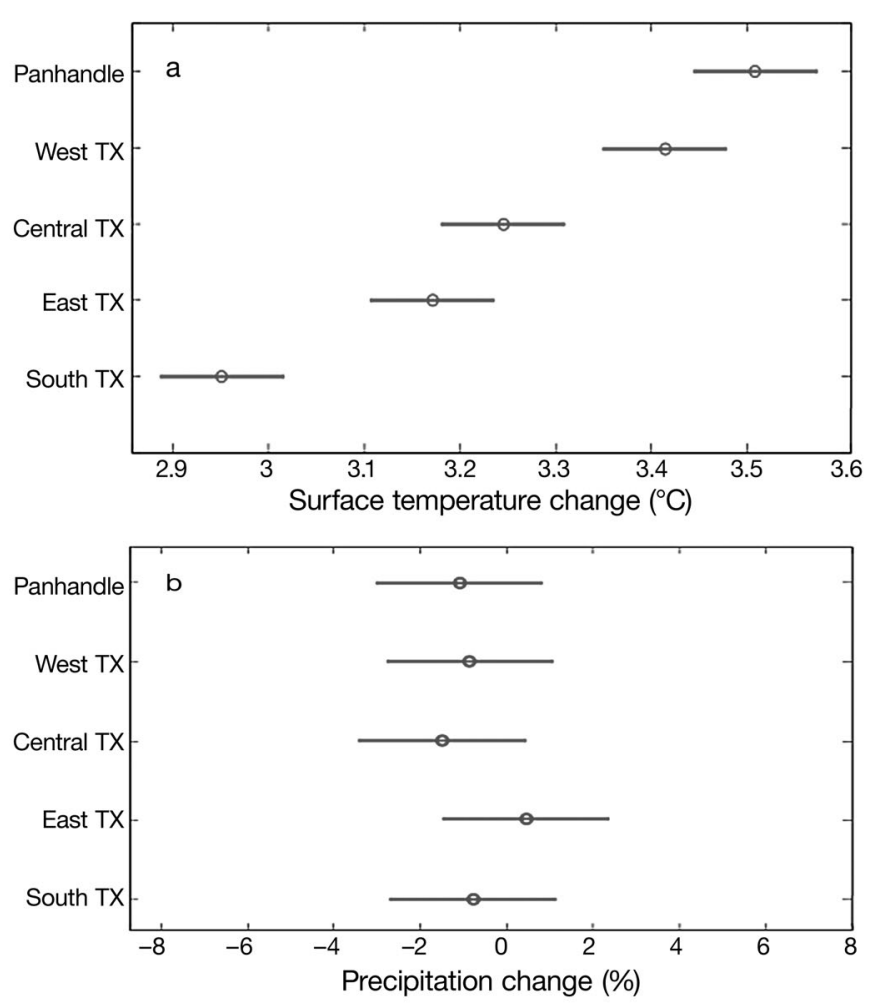

Fig. 11. The $95 \%$ confidence intervals for (a) surface air temperature and (b) precipitation changes between 2070-2099 and 1971-2000 under the A1B scenario for the 5 sub-regions over Texas (TX)

precipitation in this area. These results suggest that moisture sources, atmospheric circulations, topography, and locations have important roles in future changes in precipitation and temperature in different sub-regions of Texas. Historically, the eastern half of Texas is humid subtropical, while the western half is semi-arid (with some arid regions). Northern Texas including the Panhandle region is semi-arid and experiences colder winters than the other regions of Texas. These differences also affect future temperature and precipitation patterns in different parts of Texas.

Seasonal temperature changes over 2040-2069 and 2070-2099 are shown in Fig. 14a. Temperatures in summer are more heterogeneous than those in winter. Larger temperature increases occur in the Panhandle region on an annual basis and in summer. The temperature increases exhibit similar patterns in winter for all 5 sub-regions. Still, the magnitudes in temperature increase in summer are larger than those in winter. For precipitation changes, the magnitudes are amplified as temperatures continue to rise (Fig. 14b). Precipitation changes are small on the annual scale. We conclude that different areas in
Texas are likely to experience different climate change in terms of magnitudes and timing in temperature and precipitation under the A1B scenario.

\section{RELATIONSHIPS BETWEEN PRECIPITATION AND SURFACE AIR TEMPERATURE CHANGES}

Some early studies of temperature-precipitation relationships were summarized by Madden \& Williams (1978), who computed correlations between temperature and precipitation in the contiguous USA and Europe for the period 1897-1960. They found strong negative correlations in summer, strongest in the central and southern Great Plains, which includes Texas. They also found that cold winters were mostly wet in the plains states.

Fig. 15a shows that there is a negative relationship between annual precipitation and temperature changes under the A1B scenario as projected by the 16 climate models. The regression slope is $-7 \%{ }^{\circ} \mathrm{C}^{-1}$,
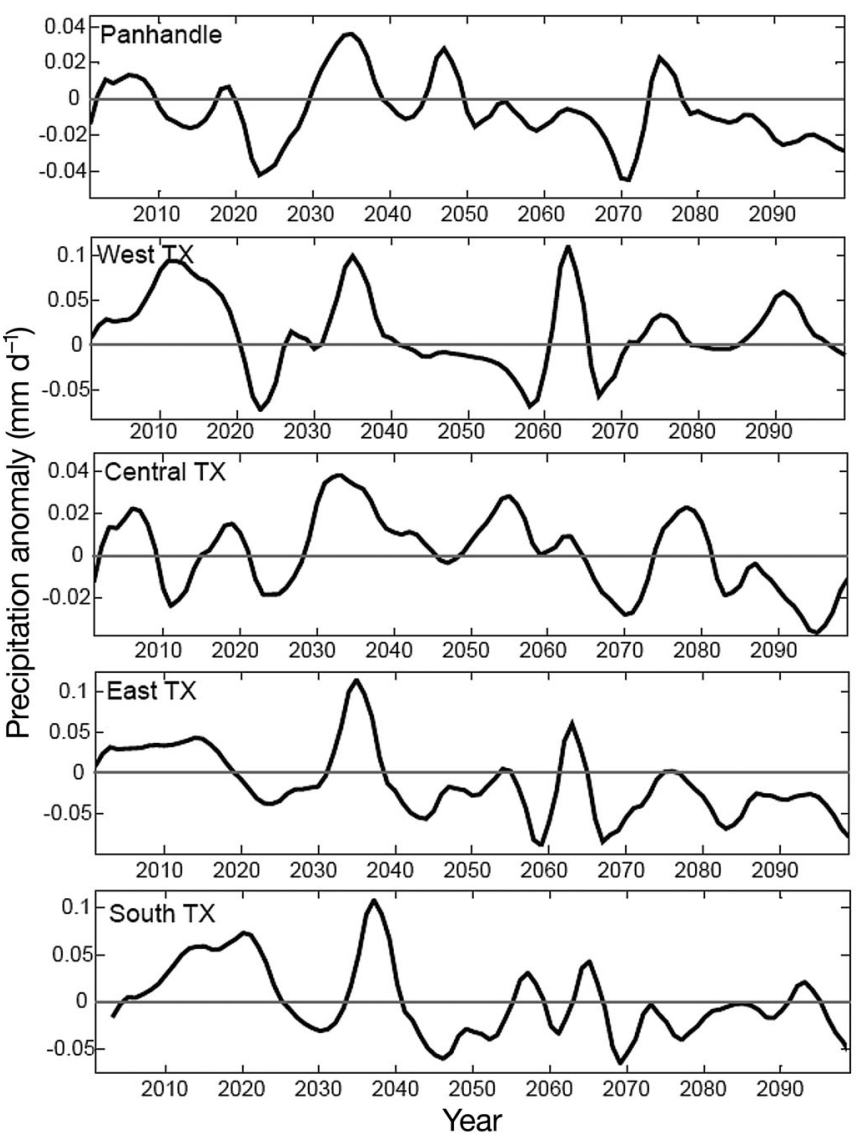

Fig. 12. Projected precipitation anomalies relative to 19712000 means after applying wavelet analysis to the ensemble mean of all downscaled model outputs in the 5 sub-regions over Texas. Note the different $y$-axis scales 


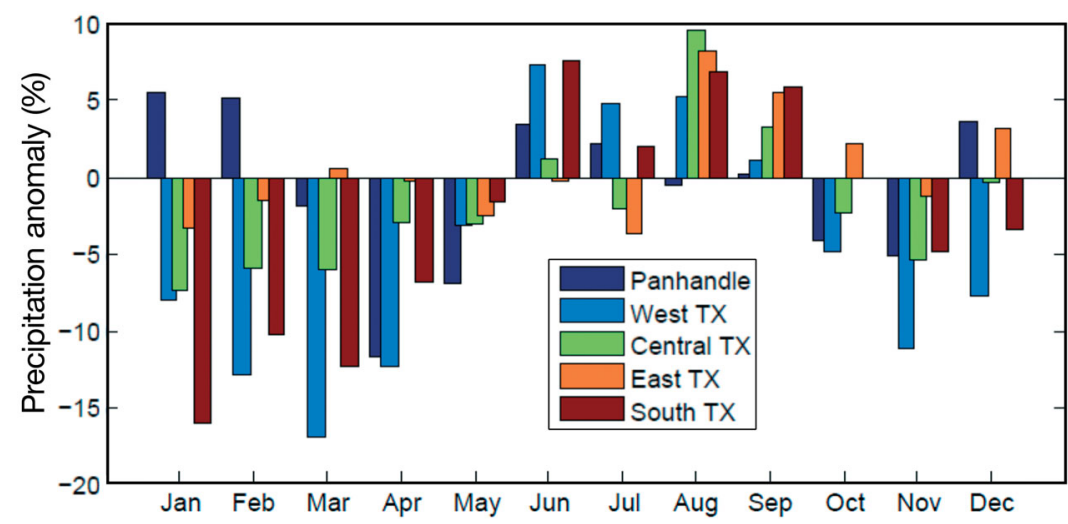

Fig. 13. Projected monthly precipitation anomalies under the A1B scenario for the period 2070-2099 relative to 1971-2000 means in the 5 sub-regions of Texas mer precipitation and temperature changes is consistent with Madden \& Williams (1978). Fig. 15b also shows that in summer, when temperature increases are small, precipitation is expected to increase. Thus, summers in Texas tend to be either hot and dry or cool and wet. This indicates that the role of large-scale dynamics in summer is diminished, and reduced precipitation is associated with less soil moisture and thus a higher Bowen ratio (or higher sensible heat fluxes and lower latent heat fluxes). The GFDL-CM2.1 and IPSL-CM4 climate models perform best in simulating precipitation in Texas, while CNRM-CM3 produces the smallest correlation between model results and observations. The results for the 5 sub-regions in Texas (not shown here) exhibit similar relationships between precipitation anomalies and temperature changes. The precipitation and temperature relationships in Texas are different from those reported in Held \& Soden (2006), suggesting that regional climate change signals are not always on the same order as those on the global scale.

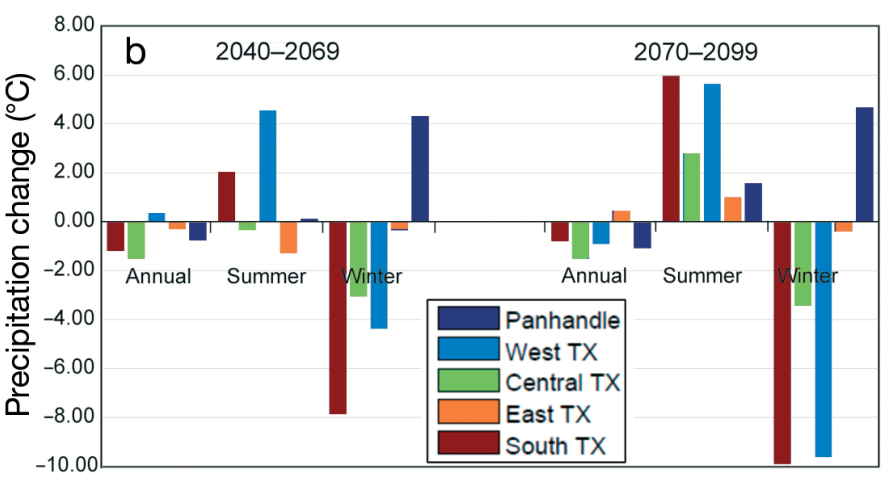

Fig. 14. Ensemble means of (a) temperature and (b) precipitation changes under the A1B scenario in the 5 sub-regions over Texas (TX)

indicating an overall drying trend in the 21 st century. The projected correlation between summer precipitation and temperature changes is negative (Fig. 15b). In winter, precipitation changes are not highly correlated with temperature changes (Fig. 15c). This suggests that changes in summer precipitation are very sensitive to changes in surface air temperature in a warming climate, while winter precipitation changes are not. This relationship for sum-

\section{CONCLUSIONS}

The comparison of downscaled model results with observations (NCDC and NARR) shows that the models reproduce the main features of surface air temperature and precipitation for the present-day climate, although there are model-to-model variations in both temperature and precipitation. GFDLCM2.1 and IPSL-CM4 perform best in simulating precipitation in Texas.

Our probability analysis shows an overall increase in temperature towards the end of the 21st century, with ensemble mean increases of $4.8,3.6$, and $2.2^{\circ} \mathrm{C}$ for the A2, A1B, and B1 scenarios, respectively. Temperatures in northwestern Texas are projected to increase more, ranging from 2.4 to $4.2^{\circ} \mathrm{C}$ under different scenarios, while temperatures increase steadily in southeastern Texas in response to the large thermal capacity of the Gulf of Mexico. These detailed regional features are not present in coarseresolution GCM projections (IPCC 2007). The trends in precipitation are not as conspicuous as those in temperatures, suggesting the involvement of more complicated mechanisms. Overall, precipitation decreases under the $\mathrm{A} 1 \mathrm{~B}$ and $\mathrm{A} 2$ scenarios. Under the 

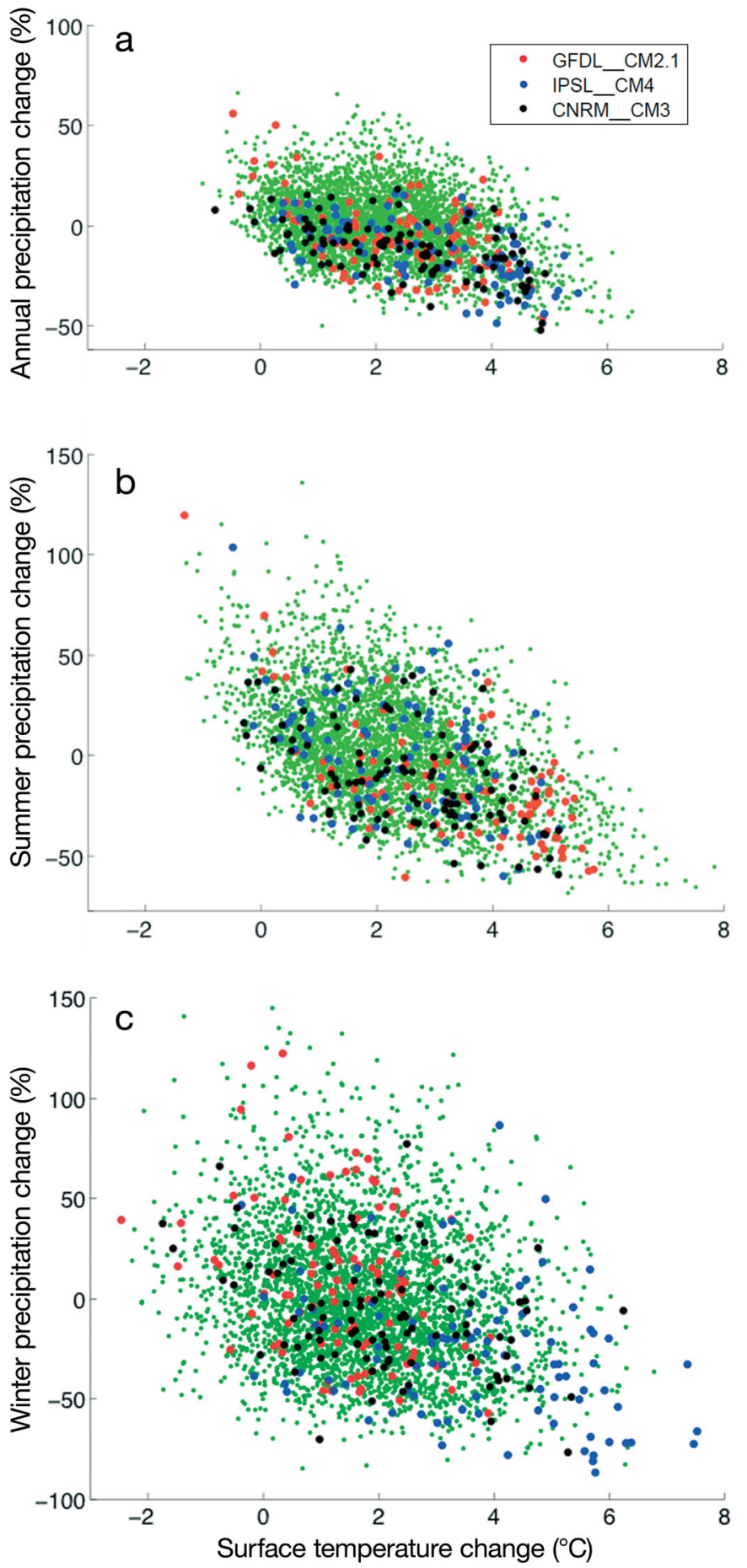

Fig. 15. (a) Annual, (b) summer, and (c) winter hydrologic sensitivities in the 21st century over Texas under the A1B scenario. Annual, summer, and winter precipitation and surface air temperature changes are averaged for the period 2001-2099 relative to 1971-2000 means. Each point represents one model result at one specific year over the period 2001-2099. There are $39 \times 99$ points for the 39 model runs provided by 16 climate models. Green dots: results from the 13 models other than CNRM-CM3, IPSL-CM4, and GFDL-CM2.1
B1 scenario, there is a wetting trend. Precipitation variability decreases in winter and increases in summer in a southwest-northeast direction, with big changes in the southwest. Most of Texas, except for the Panhandle region, is projected to experience reduced rainfall in winter. In contrast, summer seasons are projected to become much wetter over southwestern Texas. By use of wavelet analysis for precipitation changes, we found drying trends in 4 of 5 sub-regions, except West Texas. Under future global warming, the magnitudes of regional precipitation change in different sub-regions are projected to be different from the global trends (IPCC 2007). Observations also show that regional precipitation changes in Texas during the past few decades are different from the global precipitation trends (e.g. Mishra \& Singh 2010). Analysis of the relationships between precipitation and surface air temperature changes suggests an overall negative correlation between precipitation and temperature changes on an annual basis, while there is no clear correlation in winter. The relationship in summer is negative, suggesting a high sensitivity of summer precipitation to temperature changes.

The US Global Change Research Program has provided a comprehensive assessment of future climate across the USA, and the results from the present study will add more details of future climate change for the Texas region to help the state prepare for the future climate change impacts.

Uncertainties associated with future climate projections, including the representation of future greenhouse gases emissions scenarios, use of bias correction in downscaling the coarse-resolution climate simulations to regional scale, and parameterizations used in climate models, have not been fully addressed here. Future studies concerning model uncertainties are needed to better quantify the changes. In addition, given the fact that the precipitation and temperature data are only at a monthly scale, this study did not assess the downscaled model results in simulating daily precipitation and temperature, extremes and variability, which are important for some applications, e.g. hydrologic impacts such as flooding. A lot of effort is being put into improving climate projections at regional scales. One example is the North American Regional Climate Change Assessment Program (NARCCAP), which is an international program to produce high-resolution climate change simulations in order to investigate uncertainties in regional scale projections of future climate and generate climate change scenarios for use in impacts research (Mearns et al. 2009). 
Acknowledgements. This research is supported by NASA Headquarters under the NASA IDS grants NNX07AL79G and NNX11AE43G and the NASA Earth and Space Science Fellowship (NESSF) Program grant NNX07AO28H. We thank the Texas Advanced Computing Center for computing resources. We acknowledge the modeling groups, the Program for Climate Model Diagnosis and Intercomparison (PCMD) and the WCRP's Working Group on Coupled Modeling (WGCM) for their roles in making available the WCRP CMIP3 multi-model data set. Support of this data set is provided by the Office of Science, US Department of Energy. We also thank Lisa Helper and 2 reviewers for their thoughtful comments.

\section{LITERATURE CITED}

Almasri A, Locking H, Shukar G (2008) Testing for climate warming in Sweden during 1850-1999 using wavelet analysis. J Appl Stat 35:431-443

- Boer GJ, Flato G, Ramsden D (2000) A transient climate change simulation with greenhouse gas and aerosol forcing: projected climate to the twenty-first century. Clim Dyn 16:427-450

Cameron GN, Scheel D (2001) Getting warmer: effect of global climate change on distribution of rodents in Texas. J Mammal 82:652-680

Cayan DR, Maurer EP, Dettinger MD, Tyree M, Hayhoe K (2008) Climate change scenarios for the California region. Clim Change 87(Suppl 1):21-42 doi:10.1007/s10584-0079377-6

Dean A, Voss D (1999) Design and analysis of experiments. Springer Verlag, New York, NY

Fowler HJ, Ekström M, Blenkinsop S, Smith AP (2007) Estimating change in extreme European precipitation using a multimodel ensemble. J Geophys Res 112:D18104 doi: 10.1029/2007JD008619

Held IM, Soden BJ (2006) Robust responses of the hydrological cycle to global warming. J Clim 19:5686-5699

Higgins RW, Shi W, Yarosh E (2000) Improved United States precipitation quality control system and analysis. NCEP/Climate Prediction Center Atlas No. 7. US Department of Commerce, NOAA, National Weather Service, Camp Springs, MD. Available at: www.cpc.ncep.noaa. gov/research_papers/ncep_cpc_atlas/7/index.html

IPCC (2001) Climate change 2001: the scientific basis - contribution of Working Group I to the Third Assessment Report of the Intergovernmental Panel on Climate Change. Cambridge University Press, Cambridge

IPCC (2007) Climate change 2007: the scientific basis - contribution of Working Group I to the Fourth Assessment Report of the Intergovernmental Panel on Climate Change. Cambridge University Press, New York, NY

Jiang X, Wiedinmyer C, Chen F, Yang ZL, Lo JCF (2008) Predicted impacts of climate and land use change on surface ozone in the Houston, Texas area. J Geophys Res 113:D20312

Johns TC, Gregory JM, Ingram WJ, Johnson CE and others (2003) Anthropogenic climate change for 1860 to 2100 simulated with the HadCM3 model under updated emissions scenarios. Clim Dyn 20:583-612 doi:10.1007/ s00382-002-0296-y

Kalnay E, Cai M (2003) Impact of urbanization and land-use change on climate. Nature 423:528-531
Karl TR, Trenberth KE (2003) Modern global climate change. Science 302:1719-1723

Kidson JW, Thompson CS (1998) A comparison of statistical and model-based downscaling techniques for estimating local climate variations. J Clim 11:735-753

Liang XZ, Pan J, Zhu J, Kunkel KE, Wang JXL, Dai A (2006) Regional climate model downscaling of the U.S. summer climate and future change. J Geophys Res 111: D10108 doi:10.1029/2005JD006685

> Liang XZ, Kunkel KE, Meehl GA, Jones RG, Wang JXL (2008) Regional climate models downscaling analysis of general circulation models present climate biases propagation into future change projections. Geophys Res Lett 35:L08709 doi:10.1029/2007GL032849

Lo JCF, Yang ZL, Pielke RA (2008) Assessment of three dynamical climate downscaling methods using the Weather Research and Forecasting (WRF) model. J Geophys Res 113:D09112 doi:10.1029/2007JD009216

> Loaiciga HA, Maidment DR, Valdes JB (2000) Climatechange impacts in a regional karst aquifer, Texas, USA. J Hydrol (Amst) 227:173-194

> Madden RA, Williams J (1978) The correlation between temperature and precipitation in the United States and Europe. Mon Weather Rev 106:142-147

Maurer EP (2007) Uncertainty in hydrologic impacts of climate change in the Sierra Nevada Mountains, California under two emissions scenarios. Clim Change 82: 309-325

> Mearns LO, Rosenzweig C, Goldberg R (1997) Mean and variance change in climate scenarios: methods, agricultural applications, and measures of uncertainty. Clim Change 35:367-396

> Mearns LO, Bogardi I, Giorgi F, Matyasovszky I, Palecki M (1999) Comparison of climate change scenarios generated from regional climate model experiments and statistical downscaling. J Geophys Res 104(D6): 6603-6621

> Mearns LO, Gutowski WJ, Jones R, Leung LY, McGinnis S, Nunes AMB, Qian Y (2009) A regional climate change assessment program for North America. EOS Trans Am Geophys Union 90:311-312

Meehl GA, Covey C, Delworth T, Latif M and others (2007) The WCRP CMIP3 multi-model dataset: a new era in climate change research. Bull Am Meteorol Soc 88: 1383-1394

> Mesinger F, DiMego G, Kalnay E, Mitchell K and others (2006) North American regional reanalysis. Bull Am Meteorol Soc 87:343-360

> Mishra AK, Singh VP (2010) Changes in extreme precipitation in Texas. J Geophys Res 115:D14106 doi:10.1029/ 2009JD013398

> Murphy J (1999) An evaluation of statistical and dynamical techniques for downscaling local climate. J Clim 12: 2256-2284

Nakicenovic N, Alcamo J, Davis G, de Vries B and others (2000) Intergovernmental Panel on Climate Change special report on emissions scenarios. Cambridge University Press, Cambridge

Patz JA, Campbell-Lendrum D, Holloway T, Foley JA (2005) Impact of regional climate change on human health. Nature 438:310-317

> Schmidli J, Goodess CM, Frei C, Haylock MR, Hundecha Y, Ribalaygua J, Schmith T (2007) Statistical and dynamical downscaling of precipitation: an evaluation and compar- 
ison of scenarios for the European Alps. J Geophys Res 112:D04105 doi:10.1029/2005JD007026

> Seager R, Ting M, Held I, Kushnir Y and others (2007) Model projections of an imminent transition to a more arid climate in southwestern North America. Science 316:1181-1184

Walther GR, Post E, Convey P, Menzel A and others (2002) Ecological responses to recent climate change. Nature 416:389-395

Wentz FJ, Ricciardulli L, Hilburn K, Mears C (2007) How much more rain will global warming bring? Science 317: 233-235

Editorial responsibility: Bryson Bates, Wembley, Australia
Wilby RL, Wigley TML (1997) Downscaling general circulation model output: a review of methods and limitations. Prog Phys Geogr 21:530-548

Wood AW, Maurer EP, Kumar A, Lettenmaier DP (2002) Long-range experimental hydrologic forecasting for the eastern United States. J Geophys Res 107(D20):4429 doi:10.1029/2001JD000659

> Wood AW, Leung LR, Sridhar V, Lettenmaier DP (2004) Hydrologic implications of dynamical and statistical approaches to downscaling climate model outputs. Clim Change 62:189-216

Submitted: January 17, 2011; Accepted: February 20, 2012

Proofs received from author(s): June 30, 2012 